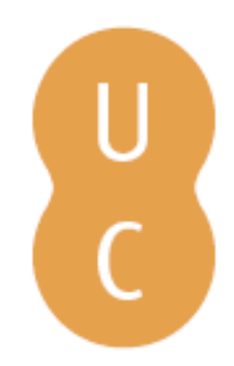

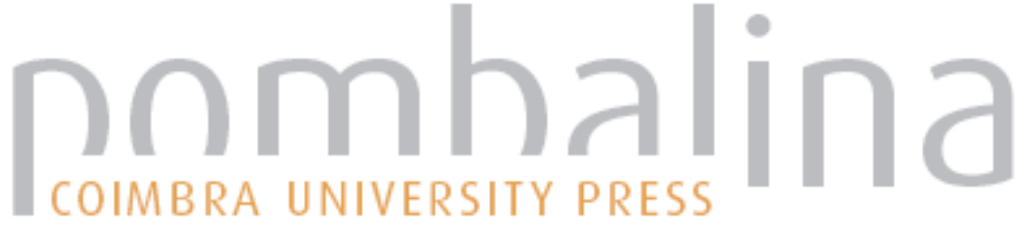

Musas errantes: tesouros da Antiguidade Clássica no labirinto da Biblioteca Nacional Brasileira

\author{
Autor(es): $\quad$ Pinheiro, Ana Virginia
}

Publicado por: Imprensa da Universidade de Coimbra

URL

persistente: $\quad$ URI:http://hdl.handle.net/10316.2/37050

DOI: $\quad$ DOI:http://dx.doi.org/10.14195/978-989-26-1043-6_2

Accessed : $\quad$ 26-Apr-2023 06:31:26

A navegação consulta e descarregamento dos títulos inseridos nas Bibliotecas Digitais UC Digitalis, UC Pombalina e UC Impactum, pressupõem a aceitação plena e sem reservas dos Termos e Condições de Uso destas Bibliotecas Digitais, disponíveis em https://digitalis.uc.pt/pt-pt/termos.

Conforme exposto nos referidos Termos e Condições de Uso, o descarregamento de títulos de acesso restrito requer uma licença válida de autorização devendo o utilizador aceder ao(s) documento(s) a partir de um endereço de IP da instituição detentora da supramencionada licença.

Ao utilizador é apenas permitido o descarregamento para uso pessoal, pelo que o emprego do(s) título(s) descarregado(s) para outro fim, designadamente comercial, carece de autorização do respetivo autor ou editor da obra.

Na medida em que todas as obras da UC Digitalis se encontram protegidas pelo Código do Direito de Autor e Direitos Conexos e demais legislação aplicável, toda a cópia, parcial ou total, deste documento, nos casos em que é legalmente admitida, deverá conter ou fazer-se acompanhar por este aviso.

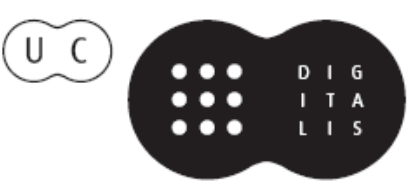


politica no Brasil do sécu

Categorias aristotélicas por Silvestre Pinheiro Ferreira - Musas errantes: tesouros da Antiguidade Clássica no labirinto da Biblioteca Nacional Brasileira - Eudoro de Sousa e a Mitologia • Câmara Cascudo em defesa de Epicuro - Medéia carioca - Ecos de Platão em Vergílio Ferreira - Imaginário clássico na poesia de António Arnaut - Motivos clássicos na poesia novilatina em Portugal: Manuel da Costa - Uma Ifigénia portuguesa: "Noite escura" de João Canijo • Uma leitura de Mau Tempo no Canal de Vitorino Nemésio $\bullet A$ phýsis grega e o Brasil: as viagens de Von Martius $\bullet$ Fantasia para dois coronéis e uma piscina. Ecos clássicos num contexto do séc. XX

\section{A RECEPÇÃO DOS CLÁSSICOS EM PORTUGAL E NO BRASIL}

Maria de Fátima Silva Maria das Graças de Moraes Augusto COORDENAÇÃo 


\section{SÉRIE MITO E (RE)ESCRITA}

ISSN: $2182-8814$

\section{PERIODICIDADE: Anual}

Apresentação: Poetas, pintores, escultores, na Antiguidade, familiarizados com mitos antigos de deuses e de homens, que cristalizavam experiências, interrogaçóes, respostas quanto à existência do homem no tempo e no mundo, em mitos se inspiraram, em contínua criação-recriaçẩo, para neles verterem a sua própria experiência temporal, com todos os desassossegos e inquietaçóes, com todo o espanto, horror ou encantamento pela excecionalidade da ação humana, que rasga ou ilumina fronteiras de finitude. Esses percursos da criação merecem, hoje, a atenção e análise dos Estudos Literários e, como não podia deixar de ser, dos Estudos Clássicos, muito peculiarmente. Importa, pois, proceder à publicação sistemática de estudos deste cariz, que se destaquem pela qualidade científica e pela originalidade, sendo dedicados, sobretudo, a autores de língua portuguesa. Assim se dá corpo à linha editorial MITO E (RE)ESCRITA.

Este livro, realizado no âmbito do Convénio de Cooperação Académica entre o CECH - Centro de Estudos Clássicos e Humanísticos da UC - e o PRAGMA - Programa de Estudos de Filosofia Antiga da UFRJ -, reúne um conjunto de estudos sobre a recepçáo de temas e modelos greco-latinos na literatura e cultura de Portugal e Brasil.

A sua originalidade resulta da participação de diferentes culturas e das especialidades académicas diversas dos investigadores que nele participam, provenientes da Literatura, da Filosofia e da História Antiga. O lapso de tempo abrangido, que vai do séc. XVI ao XX, permite uma visáo de conjunto da evoluçáo operada no perfil cultural de ambos os países e na definição de um trajeto em boa parte comum. 


\title{
Musas errantes: \\ Tesouros da Antiguidade Clássica no labirinto da Biblioteca Nacional Brasileira
}

(Errant Muses: Treasures from Classical Antiquity in the labyrinth of the Brazilian National Library)

\author{
Ana Virginia Pinheiro \\ Fundação Biblioteca Nacional (Brasil) \\ Universidade Federal do Estado do Rio de Janeiro \\ (anavirginiapinheiro@oi.com.br)
}


Página deixada propositadamente em branco 
Resumo - Aborda as práticas de catalogação dos textos impressos artesanalmente em grego e em outras línguas consideradas "exóticas", do acervo da Biblioteca Nacional Brasileira, e suas condições de localização e acesso, e propõe solução para o resgate dessa memória, ainda por desvelar.

PALAVRAS-CHAVE - Impressos em grego. Impressos em línguas exóticas.

Abstract - This article addresses the cataloging practices of handmade printed texts in Greek and other languages considered "exotic", belonging to the National Library of Brazil, as well as its location and access conditions, and proposes the solution to recover this memory, even for unveiling.

KeY-words - Printed Manuscripts in Greek. Printed Manuscripts in Exotic Languages.

Categorias são exclusivas, a leitura não o é-ou não deveria ser. [...] cada biblioteca tiraniza o ato de ler e força o leitor - o leitor curioso, o leitor alerta - a resgatar o livro da categoria a que foi condenado. Alberto Manguel ${ }^{1}$

O título deste ensaio sobre a recepção dos clássicos, especificamente, sobre o acesso a textos impressos artesanalmente em grego, disponíveis no acervo da Biblioteca Nacional do Brasil, foi inspirado em parte do título da edição latina dos Emblemata de Albertinus², que citou as nove musas, consagradas na mitologia grega como filhas de Zeus (rei dos Olímpicos) e Mnemósine (deusa da Memória), para explicar como era a ordem dos livros na Biblioteca de Alexandria - uma biblioteca modelar, desenvolvida em torno do Mouseion, o templo das musas, o lugar de produção e de preservação das artes e das ciências.

Se Calíope (Eloquência), Clio (História), Érato (Verso erótico), Euterpe (Poesia lírica, Música), Melpômene (Tragédia), Polímnia (Hinos Sagrados, Música cerimonial), Tália (Comédia), Terpsícore (Dança) e Urânia (Astronomia e Astrologia) eram musas capazes de inspirar a criação registrada em múltiplos suportes, os lugares de salvaguarda desses registros transformaram-se em labirintos, em bibliotecas carentes de desvelamento de tesouros que permanecem desconhecidos, em espaços que não motivam nem garantem sua própria longevidade.

\footnotetext{
Manguel 1997: 227.

2 Albertinus 1649.
} 
A pesquisa em bibliotecas sempre esteve alicerçada na organização, na concepção de catálogos funcionais, que traduzem os conteúdos das obras, das ideias, das mensagens objetivas ou subjetivas de um universo documentário específico e em desenvolvimento. No entanto, nem sempre os catálogos representam os acervos que teoricamente inventariam.

A verdade sobre a concepção de catálogos de bibliotecas é unívoca: constituem a expressão da visão do bibliotecário no momento da catalogação; isto é, o catálogo exibe a visão condicionada do bibliotecário - limitada a determinado número de pontos de acesso, comumente, para não sobrecarregar os sistemas eletrônicos delineados segundo padrão regular para bibliotecas correntes, de acervo continuamente atualizado; limitada à erudição de um catalogador que nem sempre tem domínio do conhecimento que é objeto da catalogação; limitada a procedimentos cerceadores que categorizam o autor, a obra, os assuntos em estrutura sistêmica pré-determinada por conveniências arbitrárias, de modo a configurar linguagem internacional - limitada, delimitada.

Essas limitaçôes são as principais causas das contínuas "descobertas" de cimélios em acervos que se assemelham a sítios arqueológicos, embora estejam catalogados.

A catalogação de obras impressas nas bibliotecas de todo o mundo segue padróes consagrados, que relevam o modo como o pesquisador naturalmente as procuraria.

O processo de busca em bibliotecas, mesmo com critérios eleitos naturalmente pelo pesquisador, exige o conhecimento desses padróes, que objetivam estabelecer ou manter o caráter mmemônico atribuído aos catálogos, desde sempre ${ }^{3}$. Porque, desde sempre, as bibliotecas investem em métodos e metodologias que contemplam a unificação de procedimentos, a integraçáo de sistemas de informação que atendem a valores de cada época - a biblioteca exaustiva, que reunia todos os livros; a biblioteca seletiva, de conteúdos determinados conforme a necessidade de formação de eruditos; e a biblioteca ideal, organizada para tornar acessível o conhecimento que intenta captar.

A ideia de biblioteca exaustiva está centrada na teoria da biblioteca alexandrina, identificada como biblioteca universal, numa referência à Biblioteca de Alexandria, criada no século III a. C., "com o objectivo de promover o helenismo e toda a sua cultura"4; monumentalizada pelas co-

\footnotetext{
3 Cf. IFLA 2009.

4 Dias 2011: 218
} 
leçóes que incorporou, tais como os livros que pertenceram a Aristóteles 5 , e que ficou famosa pelo número de vezes que se reconstruiu e se perdeu, depois de saques e incêndios documentados na História do Livro e das Bibliotecas ${ }^{6}$.

O conceito de biblioteca alexandrina deve remeter ao de biblioteca única, memorial, posto que universal, com todos os livros, de todos os autores, de todos os assuntos, devidamente ordenados. Evidentemente, desde a Antiguidade, esta era uma grande biblioteca em construção, porque "os livros podem ser continuamente acumulados"7. Se no passado sua existência estava circunscrita a um lugar, no futuro, só seria possível como biblioteca atomizada, em pequenos, médios e grandes segmentos, distribuídos por todo o mundo, cooperantes, com uniformidade de procedimentos e todas as versóes possíveis de textos anteriores e coetâneos, desde os manuscritos em rolos de papiro e pergaminho aos registros digitais, e que muitos acreditam traduzir-se, hoje, na Web.

No princípio, a partir do terceiro milênio a. C., a biblioteca era ordenada segundo o modelo de formaçáo de um erudito, determinado pelo Trivium - o conhecimento da Gramática, da Retórica e da Lógica; até incorporar, na Baixa Idade Média e até à Renascença, o modelo do Quadrivium - o conhecimento da Aritmética, da Geometria, da Música e da Astronomia ${ }^{8}$. A soma de todos esses conhecimentos reconhecia no erudito sólida formação em Artes ${ }^{9}$ e o habilitava ao uso de bibliotecas. Essas bibliotecas, até os séculos XVI e XVII, se construíam a partir de inventários, como a Bibliotheca Universalis de Konrad Gesner ${ }^{10}$, que em cerca de 12.000 verbetes pretendeu arrolar todos os livros impressos em grego, latim e hebraico, até então, assim como "textos manuscritos, autores sábios e autores menos sábios" como a Bibliotheca Selecta de Antonio Possevino ${ }^{12}$ que, em 1593 e em sucessivas edições, opôs-se à universalidade de Gesner e compilou um cânon

5 Báez 2006: 70.

6 Battles 2003: 28-60.

7 McNeely; Wolverton 2013: 32.

8 Pernoud 1944: 126-127.

9 Horch 1985: 26.

10 Gesner 1545.

11 Chartier 1997: 109-110.

12 Possevino 1593. 
bibliográfico prescritivo, uma lista para compor uma biblioteca ideal, com "os melhores instrumentos para propagar a doutrina cristâ"13.

Desde o princípio, o padrão de procedimentos em Biblioteconomia teve forte representação na catalogação, de tal modo que se uma obra não estava inventariada ou catalogada era porque, teoricamente, "não existia", ou estava "perdida", ou a biblioteca "não a possuía". Essas circunstâncias eram e são facilmente verificáveis porque a catalogação é uma estrutura padronizada, que determina o ponto de acesso principal e o corpo da entrada, oferecendo recursos de busca e localização de uma obra.

O ponto de acesso principal, comumente, é o nome do autor, quando houver, invertido pela última parte ou pelo nome paterno, ou arranjado conforme a língua do autor.

O corpo da entrada é dividido em áreas ou zonas que, no caso de obras impressas artesanalmente, é conforme, pelo menos, à sequência: título, autoridades, dados de ediçáo, lugar de publicação, casa publicadora, a data de publicação, a extensão (em volumes, partes, tomos, páginas), as ilustrações, as dimensóes (em formatos e centímetros), a série, e as notas, de caráter geral e local.

Um fundamento, no processo de catalogação, é o respeito à grafia das palavras, à língua do texto, ao modo como o autor estruturou o título, que deve ser transcrito exatamente como aparece na página de rosto da obra catalogada. Desse modo, "todas as bibliotecas, confortavelmente, contêm escritos e justapõem ideias que, [...] lá estão, sentadas nas pratelerias, esperando que surjam aqueles estudiosos a quem caberá cotejar suas contradiçôes latentes"14.

No entanto, as bibliotecas não cresceram com equilíbrio e sua aparente organização esconde o conflito quotidiano entre os métodos de organização consagrados e seus efeitos colaterais - aqueles procedimentos e fundamentos de catalogaçáo não se aplicariam a toda e qualquer obra do acervo, por diferentes motivos, mais ou menos nobres, dependendo da ocasião. Por exemplo, quando os bibliotecários curadores de acervos enfrentaram regimes de exceção e censura que levaram ao recolhimento, à subtração, à destruição de obras, cuja guarda poderia abreviar a vida de seu possuidor, decidiram pelo acolhimento secreto dessas obras; por isto, não foram catalogadas, mas foram mantidas nos acervos. Outro exemplo: as obras impressas em alfabetos cuja expressão gráfica não é reproduzível nos sistemas bibliográficos

13 Reyes Gómez 2010: 108.

14 McNeely, Wolverton 2013: 29. 
constituídos são tratadas como obras em línguas "exóticas", no contexto das práticas em Biblioteconomia; por isto, não são catalogadas, mas mantidas nos acervos.

Tudo isto leva a uma certeza: não há simplicidade ou ingenuidade na organização de uma biblioteca, porque toda biblioteca resume o caos do estado da arte do conhecimento, em sua época, e acumula o caos de épocas anteriores.

Esta certeza se configura, por exemplo, quando se constata que os sistemas de informação, que objetivam dispor a informação através do acesso em linha, de modo livre e, preferencialmente, irrestrito, foram construídos para acervos correntes e, potencialmente, utilizáveis.

Textos de produção tipográfica artesanal (do século XV ao XVIII), em línguas clássicas, "mortas" ou que apresentem ligaduras de letras, abreviaçôes e abreviaturas e outros sinais que caíram em "desuso", são catalogados com restriçóes, a despeito do interesse crescente de seus conteúdos por pesquisas vivas, em todo o mundo.

Os sentidos de "desuso" e "restriçáo", aqui, não se aplicam ao que é antigo ou ao que passou e deixou de ter interesse; dizem respeito ao tratamento que é dado a determinadas palavras e sinais diacríticos, na catalogação, para impedir ou reduzir a ocorrência de "ruídos" em sistemas de informação que não os relevaram. O mácron $\left(^{-}\right)$, a bráquia ( $\left.{ }^{\bullet}\right)$, o anel ( $\left.{ }^{\circ}\right)$, o espírito áspero (' ), o espírito brando (' ), o parágrafo ( $\mathrm{g}$ ), o E comercial (\&), o circunflexo, a cedilha, as aspas duplas, os colchetes, o trema, as palavras hifenizadas e outros sinais, que não foram previstos na concepção desses sistemas, são omitidos ou, se transcritos, ficam irreconhecíveis, ocasionando um registro catalográfico incompleto, imperfeito.

Nessas circunstâncias, os impressos que oferecem riqueza de sinalização, assim como as ediçóes em línguas ditas "exóticas" - como o hebraico, o copta, o grego - não constam ou não são recuperáveis nos catálogos físicos e eletrônicos de bibliotecas, que náo previram a necessidade de fontes específicas ou subestimaram essas ocorrências - e este é o caso da Biblioteca Nacional Brasileira e, certamente, de muitas outras bibliotecas do Ocidente.

Então, seria lógico deduzir que na Biblioteca Nacional Brasileira existem obras impressas em línguas "exóticas" que nunca foram catalogadas?

Sim, por exemplo (Figuras 1-3): 


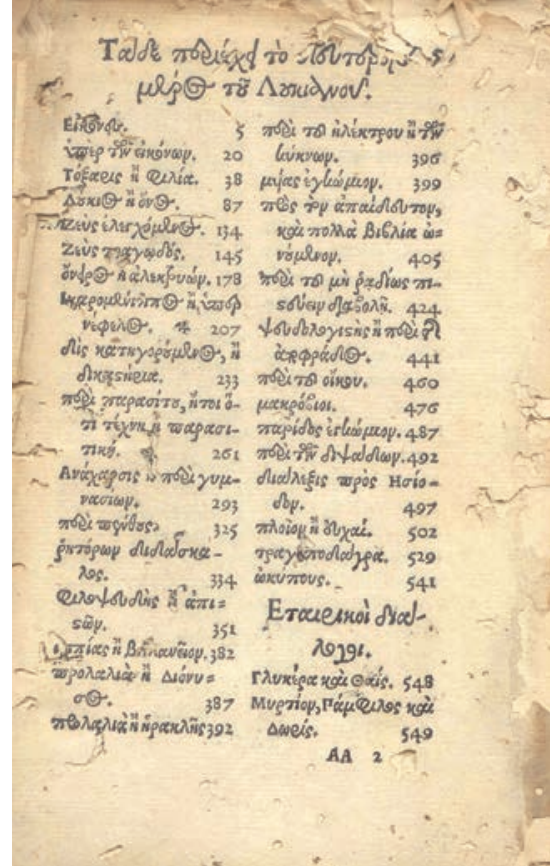

Figura 1

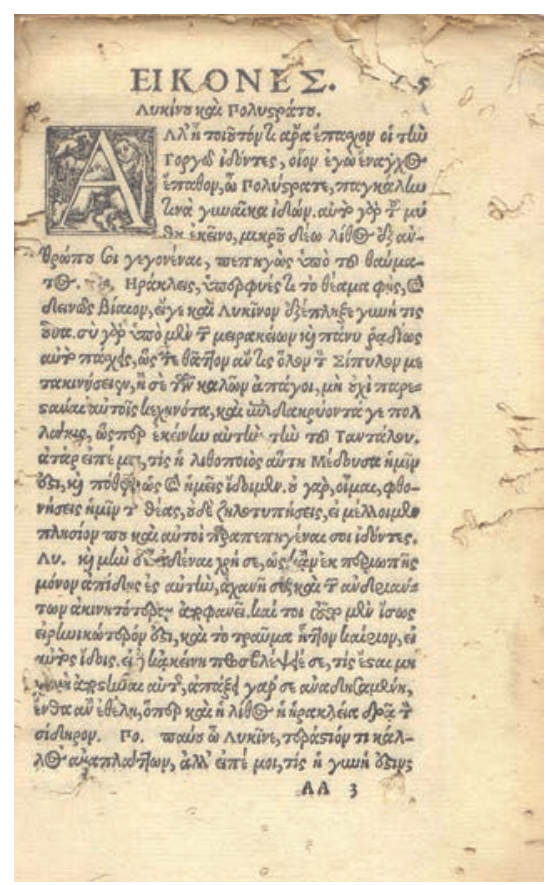

Figura 2

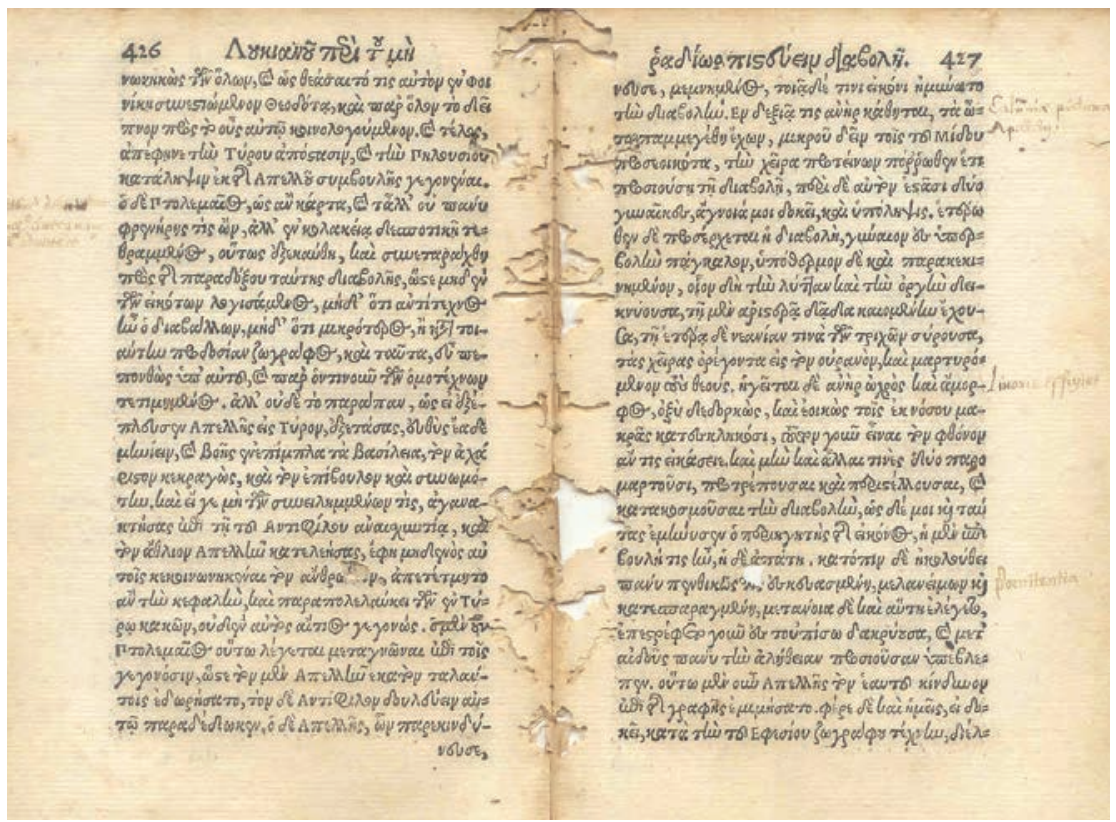

Figura 3 
Seria razoável deduzir que na Biblioteca Nacional brasileira existem obras impressas em línguas "exóticas" catalogadas de modo sumário (às vezes, incorreto), como tentativa de solução do problema de recuperação e acesso?

Sim, por exemplo (Figuras 4-5, Quadros 1-2):

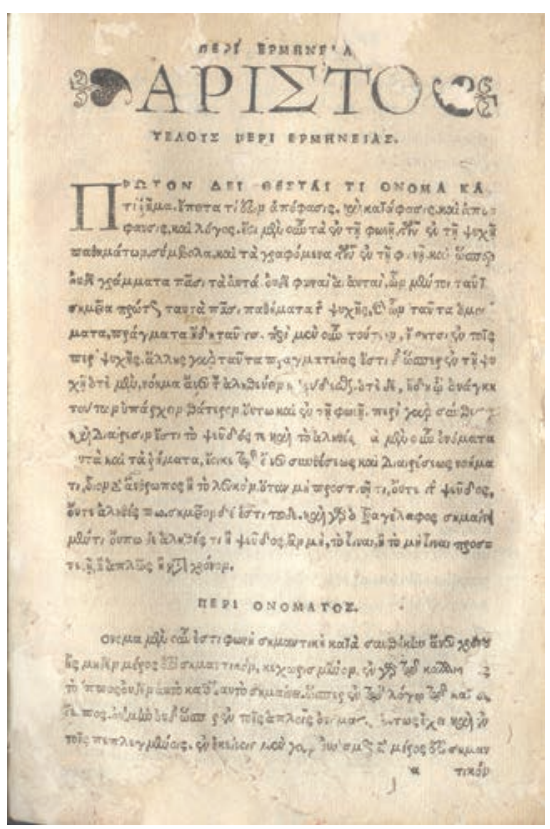

Figura 4: título de partida

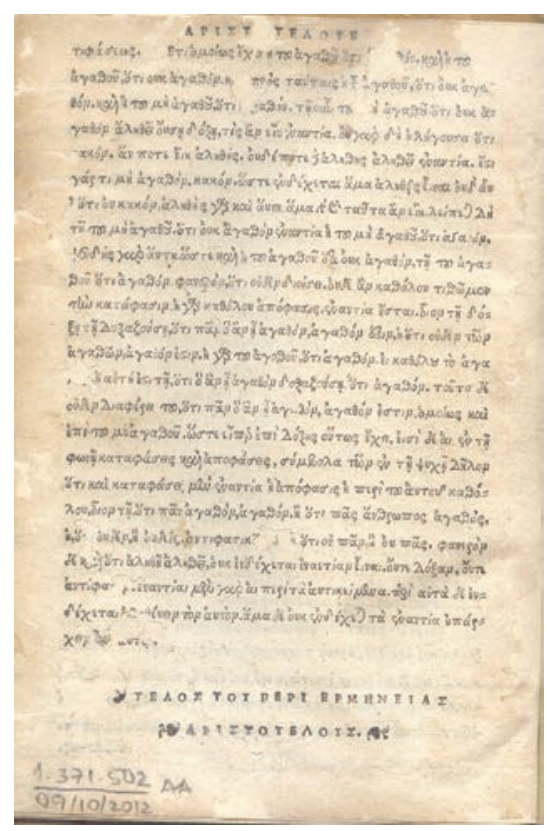

Figura 5: colofão

Quadro 1: Catalogação original

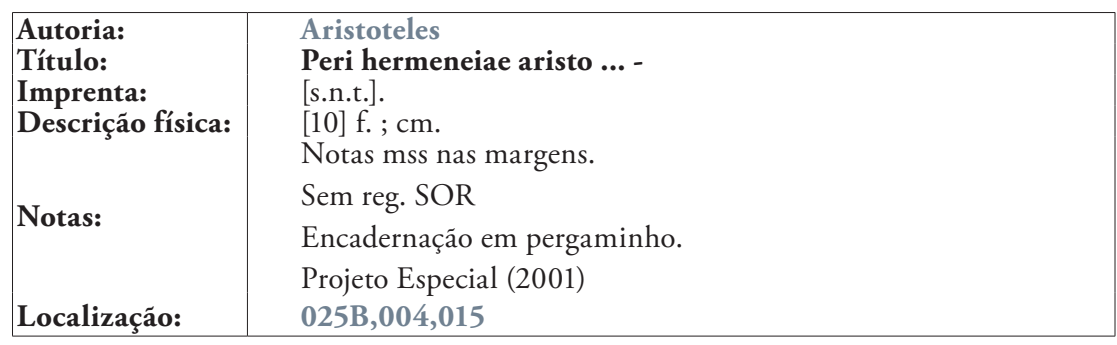


Quadro 2: Catalogação proposta

\begin{tabular}{|c|c|}
\hline Autoria: & Aristóteles \\
\hline Título uniforme & Perì Hermeneías \\
\hline Título: & Perì Hermeneías Aristo [...]. [...]. \\
\hline $\begin{array}{l}\text { Título } \\
\text { Convencionado } \\
\text { p/Arq }\end{array}$ & Organon \\
\hline Imprenta: & [S.1. : s.n., 16--?]. \\
\hline Descrição física: & [10] f. ; $20 \mathrm{~cm}$. \\
\hline Notas: & $\begin{array}{l}\text { Texto em grego. } \\
\text { Anotaçóes manuscritas (tinta): notas às margens e sublineares, ao } \\
\text { longo do texto. } \\
\text { Encadernaçáo: inteira, em pergaminho, com título à tinta no alto da } \\
\text { pasta anterior. }\end{array}$ \\
\hline $\begin{array}{l}\text { Notas para } \\
\text { inclusáo em } \\
\text { Bibliog: }\end{array}$ & $\begin{array}{l}\text { MINIO-PALUELLO, L. Aristotelis: Categoriae et Liber De Inter- } \\
\text { pretatione. Oxford: Oxonii et Typographeo Clarendoniano, } 1974 . \\
\text { Disponível em: http://folk.uio.no/amundbjo/grar/categoriae/Minio- } \\
\text {-Paluello_print.pdf. Acesso em: } 23 \text { set. } 2013 \text {. }\end{array}$ \\
\hline $\begin{array}{l}\text { Dados } \\
\text { biográficos/ } \\
\text { históricos: }\end{array}$ & $\begin{array}{l}\text { Raridade/Importânica: "Perì Hermenías" é uma das mais antigas } \\
\text { obras de Lógica, de Aristóteles. O título significa "Sobre a Interpre- } \\
\text { tação",[...] mas é conhecida, também, pela forma latina "De Inter- } \\
\text { pretatione" desde a Renascença (BOETHIU'S translation of the Pe- } \\
\text { rihermenias. Washington, DC: The Catholic University of America, } \\
1 \text { ago. 2013. Disponível em: <http://www.logicmuseum.com/oppo- } \\
\text { sition/perihermaneias.htm>. Acesso em: } 23 \text { set. } 2013 \text {; KNEALE, } \\
\text { W.; KNEALE, M. The Development of Logic. Oxford, 1971). }\end{array}$ \\
\hline Localizaçáo: & 025B,004,015 [MFN 24361] \\
\hline Microfilme: & OR-00652 (06). \\
\hline URL: & $\begin{array}{l}\text { http://objdigital.bn.br/objdigital2/acervo_digital/div_obrasraras/ } \\
\text { or1371502/or1371502.pdf }\end{array}$ \\
\hline No. Registro: & 1.371 .502 AA 09/10/2012 \\
\hline Assunto tópico: & $\begin{array}{l}\text { Verdade (Aristóteles) } \\
\text { Organon (Aristóteles) }\end{array}$ \\
\hline
\end{tabular}

Seria possível conjecturar que na Biblioteca Nacional Brasileira existem obras impressas, com anotaçôes manuscritas, de época, em línguas "exóticas", e que náo foram explicitamente apontadas e descritas nas catalogaçóes, embora pudessem fomentar pesquisas de modo extraordinário?

Sim, por exemplo (Figuras 6-7): 


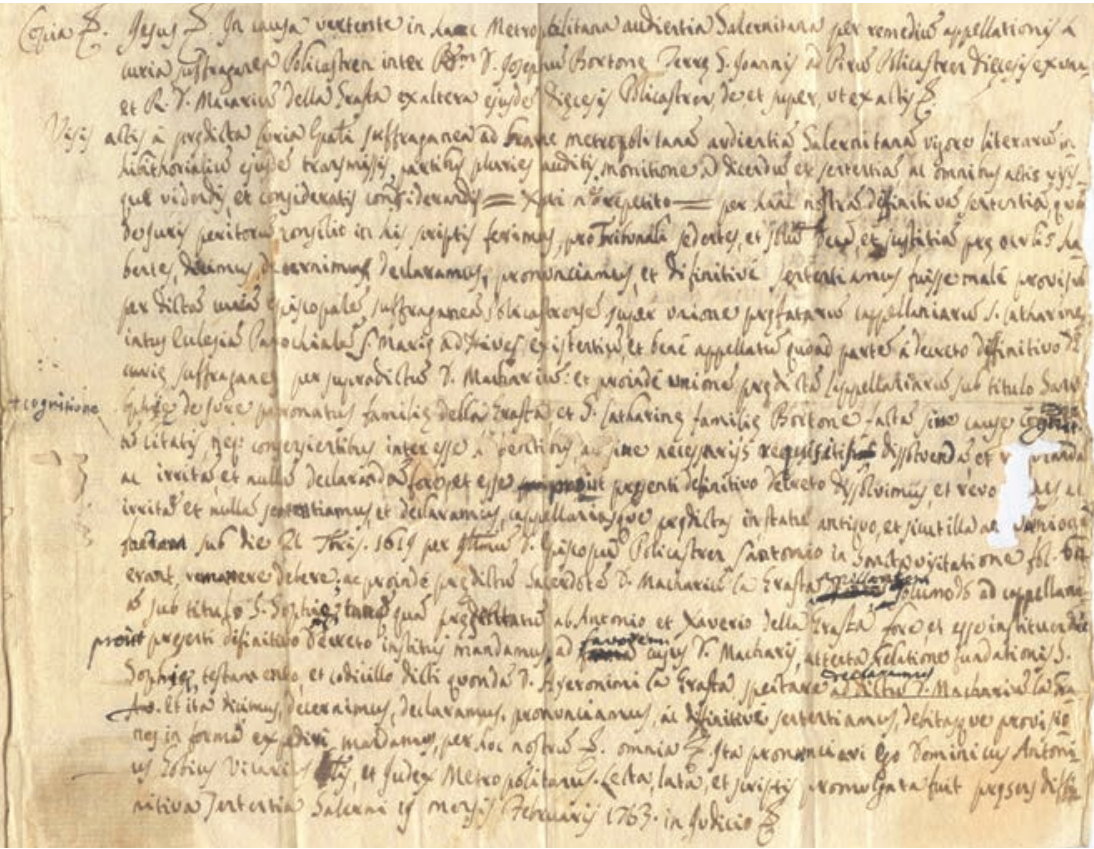

Figura 6: reto de folha inserida no Lexicon graeco-latinvm, de Joannes Scapula, 1623 (BNBr/

OR097,002BIS,001).

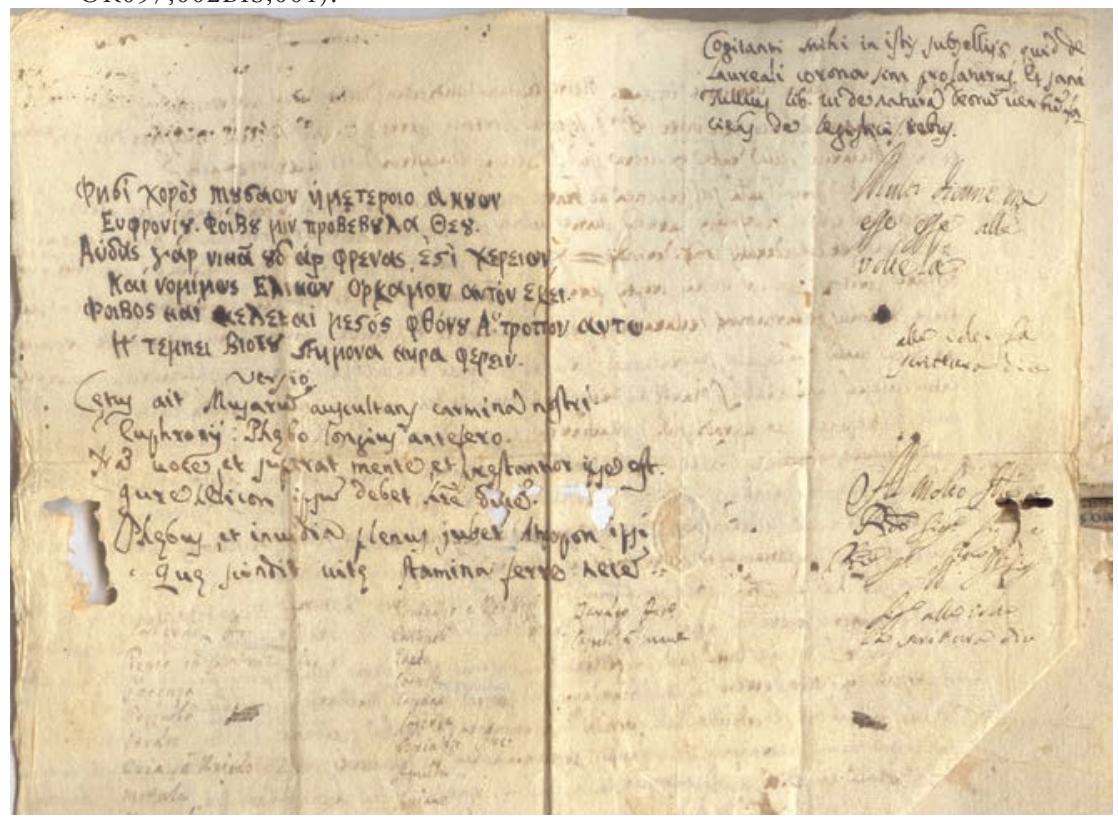

Figura 7: verso de folha inserida no Lexicon graeco-latinvm, de Joannes Scapula, 1623 (BNBr/ OR097,002BIS,001). 
Então, como solucionar essa situação de evidente desconforto para o pesquisador que, desconhecendo as intempéries do processo de catalogação de obras em línguas "exóticas", fica cada vez mais dependente de bibliotecários disponíveis e cônscios de seus deveres quanto ao oferecimento e ao acesso à informação?

Como solucionar essa situação de evidente desconforto para o bibliotecário que, diante das limitaçóes impostas pelos recursos tecnológicos da biblioteca, fica cada vez mais dependente de pesquisadores disponíveis e motivados a oferecer seu conhecimento científico para favorecer à organização da biblioteca?

Qual a prerrogativa que sobra para o pesquisador e para o bibliotecário, nessas circunstâncias, sob a contundência de cronogramas de projetos de pesquisa e desenvolvimento e de avaliaçóes acadêmicas e funcionais, respectivamente?

A quantidade de obras em línguas "exóticas", do passado, do presente e do futuro, que carecem de catalogação adequada, exige soluçóes urgentes, que dependem do compartilhamento de interesses, entre o pesquisador e o bibliotecário, centrados no fato de que a informação que está perdida deve ser difundida.

Essas soluções envolvem, por exemplo: 1 a identificação de anotaçóes manuscritas no livro impresso, de modo a distinguir as anotaçóes de bibliotecários das marcas de proveniência e de estudo, do próprio autor ou de usuários consecutivos; 2 o exame simultâneo e comparativo de exemplares de obras, para verificar incompletudes, delinear expectativas de longevidade e identificar alteraçóes de conteúdo e forma, impostas pelo tempo; e 3 a catalogação, propriamente dita, com a colaboração do pesquisador.

Se essas ou outras soluções não se efetivarem, as bibliotecas manterão coleçôes paralelas, não catalogadas ou processadas de modo imperfeito ou incompleto.

Enquanto isso, o pesquisador e o bibliotecário permanecem condenados a ansiar por "descobertas" em sua errância labiríntica, ladeados pelas musas que um dia inspiraram a ordem das bibliotecas e que ainda podem inspirar. 
Musas errantes:

Tesouros da Antiguidade Clássica no labirinto da Biblioteca Nacional Brasileira

\section{Bibliografia}

Albertinus, A. (1649), Ae. Albertini Emblemata Hieropolitica versibus et Prosa illustrabat Joannes Melitanus a Corylo eiusdem Musae Errantes. Coloniae: Apud Constantinum Munich (BNBr/OR214,002,015).

Báez, F. (2003), "Apogeu e fim da Biblioteca de Alexandria”, in História universal da destruição dos livros: das tábuas da Suméria à guerra do Iraque. Tradução Léo Schlafman. Rio de Janeiro: Ediouro: 61-73.

Battles, M. (2003), “Alexandria em chamas", in A conturbada história das bibliotecas. Tradução João Vergílio Gallerni Cuter. São Paulo: Ed. Planeta do Brasil: 28-60.

Chartier, R. (1997), A ordem dos livros. Tradução Leonor Graça. Lisboa: Passagens:109-110.

Dias, G. (2011), “Biblioteca de Alexandria: o helenismo e a dinâmica cultural dos judeus”, Humanitas 63: 217-223

IFLA (2009), Declaração de princípios internacionais de catalogação. Traduzido por Lídia Alvarenga et al. São Paulo: Federação Internacional de Associaçôes de Bibliotecários e Instituiçôes (IFLA)/UNESCO. Disponível em: <http://www.ifla.org/files/assets/cataloguing/icp/icp_2009-pt.pdf>. Acesso em: 05 ago. 2013.

Gesner, K. (1545), Bibliotheca universalis, sive Catalogus omnium scriptorum locupletissimus, in tribus linguis, latina, graeca, hebraica: extantium non extantiu, veterum recentiorum in hunc usque diem, doctorum indoctorum, publicatorum Bibliothecis latentium. Tiguri [Zurique]: apud Christophorum Froschoverum (BNBr/OR122,005,001).

Horch, R. (1985), Luzes e fogueiras: dos albores da Imprensa ao obscurantismo da Inquisição no Sacramental de Clemente Sánchez. Tese de doutoramento apresentada ao Departamento de História da Faculdade de Filosofia, Letras e Ciências Humanas da Universidade de São Paulo.

Manguel, A. (1997), Uma história da leitura. Tradução Pedro Maia Soares. São Paulo: Companhia das Letras.

McNeely, I., Wolverton, L. (2013), “A Biblioteca: 300 a.C.-500 d.C.”, in A reinvenção do conhecimento: de Alexandria à internet. Tradução de Maria Lúcia de Oliveira. Rio de Janeiro: Record: 19-48.

Pernoud, R. (1944), Lumière du Moyen Age. Paris: Bernard Grasset: 126-127.

Possevino, A. (1593), Bibliotheca selecta qua agitur de ratione studiorum in historia, in disciplinis, in salute omnium procuranda. Romae: Ex Typographia Apostolica Vaticana (BNBr/OR005,003,005).

Reyes Gómez, F. (2010), Manual de Bibliografia. Madrid: Castalia Instrumenta. 
Maria de Fátima Sousa e Silva é Professora Catedrática do Instituto de Estudos Clássicos da Universidade de Coimbra. Desenvolveu, como tese de doutoramento, um estudo sobre a Comédia Grega Antiga (Crítica do teatro na Comédia Grega Antiga), e, desde então, tem prosseguido com investigação nessa área. Publicou já traduções comentadas de nove comédias de Aristófanes, além de um volume com a tradução das peças e dos fragmentos mais significativos de Menandro.

Maria das Graças de Moraes Augusto é Professora Titular no Departamento de Filosofia do Instituto de Filosofia e de Ciências Sociais da Universidade Federal do Rio de Janeiro (UFRJ). A sua investigação sobre História da Filosofia Antiga abrange temas como Platão e a herança platónica, filosofia e conhecimento no pensamento antigo, filosofia e literatura na tradição antiga e recepção dos clássicos gregos no Brasil.

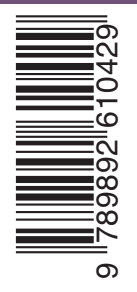


OBRA PUBLICADA

COM A COORDENAÇĀO

CIENTÍFICA
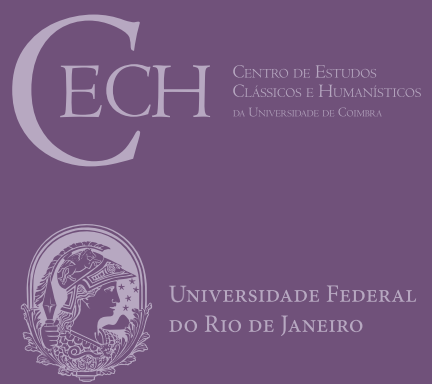

- U 